\title{
PENGARUH STRATEGI PROSES BELAJAR MENGAJAR TERHADAP PENINGKATAN PRESTASI BELAJAR SISWA (STUDI PADA SMP SWASTA RIAMA MEDAN)
}

\author{
Zulmawati \\ Surel:Zulma.wati@gmail.com
}

\begin{abstract}
This study aims to look at the effect of the teaching and learning process strategy on improving PKn student achievement at the Riama Private Middle School in Medan. The method used in this study is descriptive analysis. As for the variables in this study were independent variables $(x)$ namely the teaching learning process planning and the dependent variable (y) namely achievement student learning. Techniques and tools for data collection are by conducting observations (observation and review), questionnaires (list of written questions) to obtain information from respondents who contain questions by completing answers to choose one of the answers that are already available as where the actual situation is After all answers are collected, the data are grouped to analyze each question item in accordance with the provisions. The data processing is divided into two parts, namely data from the teacher and data from the private junior high school students in the field. The results achieved according to the method used in this study are accepted. And so that the teachers can arrange teaching plans in the learning process better.
\end{abstract}

Keywords: Strategy, Teaching and Learning Process, Learning Achievement.

\begin{abstract}
ABSTRAK
Penelitian ini bertujuan untuk melihat pengaruh strategi proses belajar mengajar terhadap peningkatan prestasi belajar PKn siswa di SMP Swasta Riama Medan. Metode yang digunakan dalam penelitian ini adalah deskriptif analisis. Adapun yang menjadi variabel dalam penelitian ini adalah Variabel bebas (x) yaitu perencanaan proses belajar mengajar dan Variabel terikat (y) yaitu prestasi belajar siswa. Teknik dan alat pengumpulan data yaitu dengan melakukan Observasi (pengamatan dan peninjauan), Angket (daftar pertanyaan tertulis) untuk memperoleh informasi dari responden yang berisi pertanyaan dengan dilengkapi jawaban untuk memilih salah satu jawaban yang sudah tersedia sebagai mana keadaan yang sebenarnya Setelah seluruh jawaban terkumpul maka data dikelompokkan untuk dianalisis setiap item pertanyaan sesuai dengan ketentuan. Pengolahan data dibagi 2 bagian yaitu data dari guru pkn dan data dari siswa SMP swasta riama medan. Hasil yang dicapai menurut metode yang digunakan dalam penelitian ini hipotesanya dapat diterima kebenarannya. Dan supaya para guru dapat menyusun rencana pengajaran dalam proses pembelajaran lebih baik lagi.
\end{abstract}

Kata kunci: Strategi, Proses belajar mengajar, Prestasi Belajar.

\section{PENDAHULUAN}

Indonesia sebagai salah satu negara sedang berkembang sudah saatnya untuk mengedepan masalah pendidikan dengan maksud untuk mengurangi kebodohan diIndonesia . 
Masalah mutu pendidikan merupakan masalah yang harus mendapat perhatian yang sungguh-sungguh. Setiap lembaga pendidikan dari TK sampai perguruan Tinggi harus selalu memfokuskan sasarannya untuk mencapai prestasi belajar siswa yang maksimal. Demikian pula tercantum dalam UU No 20 tahun 2003 tentang sistim pendidikan nasional pasal 1 butir 1 jelas tertulis bahwa". Pendidikan adalah usaha sadar dan terencana untuk mewujudkan suasana belajar dan proses pembelajaran agar peserta didik secara aktif mengembangkan potensial dirinya untuk memiliki kekuatan spiritual, keagamaan, pengendalian diri, kepribadian, kecerdasan, akhlak mulia serta keterampilan yang diperlukan dirinya, masyarakat, bangsa, negara.

$$
\text { Pendidikan nasional }
$$

berdasarkan Pancasila bertujuan untuk meningkatkan ketaqwaan kepada Tuhan YME, kecerdasan dan ketrampilan, mempertinggi budi pekerti, memperkuat kepribadian dan mempertebal semangat kebangsaan dan cinta tanah air agar dapat menumbuhkan manusia pembangunan yang dapat membangun dirinya sendiri serta bersama sama bertanggung jawab atas pembangunan bangsa. Untuk mewujudkan ini salah satunya dengan menggunakan strategi yang tepat yang akan memungkinkan prestasi belajar yang lebih optimal untuk dapat menciptakan suasana belajar maupun mutu pendidikan yang lebih optimal sekaligus akan dapat menciptakan suasana belajar maupun mutu pendidikan yang lebih tinggi serta pribadi manusia yang berguna bagi bangsa dan negara.

Melalui penelitian ini diharapkan akan tergambar apa dan bagaimana pengaruh strategi proses belajar mengajar yang tepat sehingga dapat meningkatkan prestasi belajar PKn siswa SMP Swasta Riama Medan TP 2018/2019.

\section{METODE PENELITIAN}

Metode yang digunakan dalam penelitian ini adalah deskriptif analisis. Dengan lokasi penelitian di SMP Swasta Riama Medan dengan populasi sebanyak 30 orang siswa dan 3 orang guru PKn. Adapun yang menjadi variabel dalam penelitian ini adalah Variabel bebas (x) yaitu perencanaan proses belajar mengajar PKn dan Variabel terikat (y) yaitu prestasi belajar PKn siswa.

Teknik dan alat pengumpulan data yaitu dengan melakukan Observasi (pengamatan dan peninjauan), Angket (daftar pertanyaan tertulis) untuk memperoleh informasi dari responden yang berisi pertanyaan dengan dilengkapi jawaban untuk memilih salah satu jawaban yang sudah tersedia sebagai mana keadaan yang sebenarnya dan dengan mengadakan wawncara secara lisan dengan jalan bertanya langsung. Data yang dikumpulkan ditabulasikan untuk dianalisa setiap satuan pelajaran dan setiap item pertanyaan. Selanjutnya data responden dibagi 2 yaitu Data dari guru bidang studi PKn dan data dari Siswa SMP swasta 
Zulmawati: Pengaruh Strategi Proses Belajar...

riama medan TP 2018/2019. Dalam penentuan hasil yang dicapai dengan menghubungkan data yang diperoleh dari guru dan siswa. Dalam penentuan jawaban yang diterima ataupun yang ditolak adalah berdasarkan jumlah paling banyak memilih salah satu jawaban yang disediakan dengan perincian Jawaban A (Selalu) termasuk Baik, B (kadang - kadang) termasuk sedang dan C (Tidak pernah) termasuk kurang.

Tabel 1. Tabulasi jawaban responden siswa SMP Swasta Riama Medan

\begin{tabular}{l|l|l|l|l|l}
\hline No. & $\begin{array}{l}\text { No } \\
\text { item }\end{array}$ & Jawaban A & Jawaban B & Jawaban C & Jumlah \\
\hline 1 & & 29 & 1 & - & 30 \\
2 & 1 & 20 & 7 & 3 & 30 \\
3 & 2 & 13 & 15 & 2 & 30 \\
4 & 3 & 29 & 1 & - & 30 \\
5 & 4 & 27 & 3 & - & 30 \\
6 & 5 & 25 & 5 & 5 & 30 \\
7 & 6 & 23 & 2 & - & 30 \\
8 & 7 & 28 & 2 & - & 30 \\
9 & 8 & 29 & 1 & 6 & 30 \\
10 & 9 & 18 & 6 & - & 30 \\
11 & 10 & 28 & 2 & 2 & 30 \\
12 & 11 & 7 & 21 & 9 & 30 \\
13 & 12 & 11 & 10 & - & 30 \\
14 & 13 & 29 & 1 & 4 & \\
15 & 14 & 25 & 1 & & \\
& 15 & & & & \\
\hline
\end{tabular}

Tabel 2. Tabulasi jawaban responden guru PKn SMP Swasta Riama Medan

\begin{tabular}{l|l|l|l|l|l}
\hline No & $\begin{array}{l}\text { No } \\
\text { item }\end{array}$ & Jawaban A & Jawaban B & Jawaban C & Jumlah \\
\hline $\mathbf{1}$ & & 3 & - & - & 3 \\
$\mathbf{2}$ & 1 & 3 & - & - & 3 \\
$\mathbf{3}$ & 2 & 2 & 1 & - & 3 \\
$\mathbf{4}$ & 3 & 2 & 1 & - & 3 \\
$\mathbf{5}$ & 4 & 3 & - & - & 3 \\
$\mathbf{6}$ & 5 & 1 & 2 & - & 3 \\
$\mathbf{7}$ & 6 & 3 & - & - & 3 \\
$\mathbf{8}$ & 7 & 1 & 2 & - & 3 \\
\hline
\end{tabular}


SCHOOL EDUCATION JOURNAL VOLUME 9 NO. 2 JUNI 2019

\begin{tabular}{l|l|l|l|l|l}
\hline $\mathbf{9}$ & 8 & - & 1 & 2 & 3 \\
$\mathbf{1 0}$ & 9 & 3 & - & - & 3 \\
$\mathbf{1 1}$ & 10 & 2 & - & 1 & 3 \\
$\mathbf{1 2}$ & 11 & 3 & - & - & 3 \\
$\mathbf{1 3}$ & 12 & 3 & - & - & 3 \\
$\mathbf{1 4}$ & 13 & 3 & - & - & 3 \\
$\mathbf{1 5}$ & 14 & 1 & 1 & 1 & 3 \\
$\mathbf{1 6}$ & 15 & 1 & 2 & - & 3 \\
$\mathbf{1 7}$ & 16 & 1 & 2 & - & 3 \\
$\mathbf{1 8}$ & 17 & 2 & 1 & - & 3 \\
$\mathbf{1 9}$ & 18 & 3 & - & - & 3 \\
$\mathbf{2 0}$ & 19 & 1 & 2 & - & 3 \\
\hline
\end{tabular}

Tabel 3. Persentase jawaban responden siswa SMP Swasta Riama medan

\begin{tabular}{l|l|l|l|l}
\hline $\mathbf{N o}$ & $\begin{array}{l}\text { Jawaban A } \\
\mathbf{\%}\end{array}$ & $\begin{array}{l}\text { Jawaban B } \\
\text { \% }\end{array}$ & $\begin{array}{l}\text { Jawaban C } \\
\text { \% }\end{array}$ & \% \\
\hline $\mathbf{1}$ & 96,67 & 3,33 & - & 100 \\
$\mathbf{2}$ & 66,67 & 23,33 & 10,00 & 100 \\
$\mathbf{3}$ & 43,33 & 50,00 & 6,67 & 100 \\
$\mathbf{4}$ & 96,67 & 3,33 & - & 100 \\
$\mathbf{5}$ & 90,00 & 10,00 & - & 100 \\
$\mathbf{6}$ & 83,33 & 16,67 & - & 100 \\
$\mathbf{7}$ & 76,67 & 16,67 & 16,66 & 100 \\
$\mathbf{8}$ & 93,33 & 6,67 & - & 100 \\
$\mathbf{9}$ & 96,67 & 3,33 & - & 100 \\
$\mathbf{1 0}$ & 60,00 & 20,00 & 20,00 & 100 \\
$\mathbf{1 1}$ & 93,33 & 6,63 & - & 100 \\
$\mathbf{1 2}$ & 23,33 & 70,00 & 6,67 & 100 \\
$\mathbf{1 3}$ & 36,67 & 33,33 & 30,00 & 100 \\
$\mathbf{1 4}$ & 96,67 & 3,33 & - & 100 \\
$\mathbf{1 5}$ & 83,34 & 3,33 & 13,33 & 100 \\
& & &
\end{tabular}


Zulmawati: Pengaruh Strategi Proses Belajar...

Tabel 4. Persentase jawaban responden guru PKn SMP Swasta Riama Medan

\begin{tabular}{l|l|l|l|l}
\hline No & $\begin{array}{l}\text { Jawaban A } \\
\text { \% }\end{array}$ & $\begin{array}{l}\text { Jawaban B } \\
\text { \% }\end{array}$ & $\begin{array}{l}\text { Jawaban C } \\
\text { \% }\end{array}$ & \% \\
\hline $\mathbf{1}$ & 100 & - & - & 100 \\
$\mathbf{2}$ & 100 & - & - & 100 \\
$\mathbf{3}$ & 66,67 & 33,33 & - & 100 \\
$\mathbf{4}$ & 66,67 & 33,33 & - & 100 \\
$\mathbf{5}$ & 100 & - & - & 100 \\
$\mathbf{6}$ & 33,33 & 66,67 & - & 100 \\
$\mathbf{7}$ & 100 & - & - & 100 \\
$\mathbf{8}$ & 33,33 & 66,67 & - & 100 \\
$\mathbf{9}$ & - & 33,33 & 66,67 & 100 \\
$\mathbf{1 0}$ & 100 & - & - & 100 \\
$\mathbf{1 1}$ & 66,67 & - & $-33,33$ & 100 \\
$\mathbf{1 2}$ & 100 & - & - & 100 \\
$\mathbf{1 3}$ & 100 & - & - & 100 \\
$\mathbf{1 4}$ & 100 & - & - & 100 \\
$\mathbf{1 5}$ & 33,34 & 33,33 & 33,33 & 100 \\
$\mathbf{1 6}$ & 33,33 & 66,67 & - & 100 \\
$\mathbf{1 7}$ & 33,33 & 66,67 & - & 100 \\
$\mathbf{1 8}$ & 66,67 & 33,33 & - & 100 \\
$\mathbf{1 9}$ & 100 & - & - & 100 \\
$\mathbf{2 0}$ & 33,33 & 66,67 & - & 100 \\
& & & & \\
\hline & & & & \\
\hline
\end{tabular}

\section{HASIL PENELITIAN DAN PEMBAHASAN}

Berdasarkan jawaban angket yang diberikan dan dilakukan pengolahan/interpretasi data dari jawaban siswa SMP swasta Riama dan Guru PKn SMP swasta Riama diperoleh hasil sebagai berikut:

Siswa SMP Swasta Riama medan

a. Dalam menerima pelajaran PKn dari guru PKn yang mengajar dikelas pada dasarnya mereka berminat dan memahami serta cenderung untuk mempelajarinya di rumah. Disamping itu setelah mempelajari dan mengetahui pelajaran yang diajarkan siswa berminat untuk mengembangkan dan meningkatkan pola tingkah laku keaarah yang lebih baik untuk meningkatkan prestasi yang lebih baik lagi dengan menggunakan waktu belajar dirumah secara efisien dan sebelum mulai pelajaran mereka sudah berada dikelas tanpa dipaksa tetapi oleh kesadaran sendiri agar tercapai prestasi 
yang lebih optimal. Dibuktikan dengan jawaban angket nomor $1,2,3,4,5,7,13,15$

b. Dalam ujian semester materi yang diujikan selalu sesuai dengan materi yang telah dipelajari. Siswa semua ikut ujian dan apabila mereka memperoleh nilai rendah pada saat ujian maka selalu diadakan ujian remedial. Dibuktikan dengan jawaban angket nomor 6 , 8,9

c. Setelah menerima pelajaran PKn siswa mempunyai keinginan eningkatkan aktivitas dan prestasi belajar yang lebih baik. Untuk mencapai hasil yang lebih baik guru akan mengulangi materi dengan mengadakan diskusi kelompok dikelas dan menyuruh mengerjakan tugas dirumah. Dibuktikan dengan jawaban angket nomor 10,11, 12,14

Guru PKn SMP Swasta Riama Medan

a. Kurikulum telah dipahami oleh karenanya sebelum melaksanakan proses belajar mengajar dikelas sudah terlebih dahulu membuat perangkat satuan pembelajaran (Silabus,, RPP, dll). Dibuktikan dengan jawaban angket nomor $1,2,3,4,5,8,16,17$

b. Guru didalam melaksanakan pembelajaran menggunakan metode mengajar yang sesuai dengan materi pelajaran dan setelah mengadakan ujian dan bagi siswa yang mendapat nilai rendah akan diadakan remedial.

Dibuktikan dengan jawaban angket nomor $9,10,11,12$

a. Untuk mengetahui keberhasilan belajar siswa dengan memberikan ujian sub sumatif, sumatif serta memberikan motivasi kepada siswa yang kurang berminat untuk belajar dan semester dengan menggunakan alat penilaian yang sesuai untuk pokok bahasan yang hendak dicapai . Dibuktikan dengan jawaban angket nomor $13,14,15$

b. Dalam penyusunan rencana pengajaran dalam kegiatan belajar mengajar selalu mengadakan rapat bulanan dan semesteran dan untuk mengetahui peningkatan prestasi belajar siswa dengan melihat cara belajar diluar sekolah. Dibuktikan dengan jawaban angket nomor $18,19,20$

\section{Pembuktian Hipotesis}

Berdasarkan hasil penelitian, analisa data maka dapat diatarik kesimpulan sebagai berikut

a. Minat belajar siswa untuk mendalami matri PKn bertambah meningkat karena siswa memahami materinya

b. Penyusunan rencana pembelajaran sebelumnya dapat mempermudah proses belajar mengajar dalam kelas untuk meningkatkan prestasi belajar siswa 
c. Dengan membuat strategi dalam proses belajar mengajar akan mencapai prestasi belajar yang lebih baik

d. Untuk meningkatkan prestasi belajar siswa tinjauan strategi yang terperinci, sistimatis dan terarah dapat membantu dalam tujuan yang akan dicapai

e. Dari hasil yang diperoleh dalam penelitian ini hipotesanya dapat diterima kebenarannya

\section{SIMPULAN}

Dari pembahasan diatas dapat disimpulkan Terdapat pengaruh yang signifikan dalam penggunaan strategi dalam proses belajar mengajar terhadap prestasi belajar siswa di SMP Swasta Riama. Untuk lebih memungkinkan para guru dapat menyususn rencana pembelajaran dalam proses belajar mengajar perlu kiranya mengetahui dan memahami pengertian strategi, syarat-syarat membuat atrategi yang baik dan fungsi strategi dalam mencapai tujuan yang didinginkan. Strategi dapat berfungsi sebagai pegangan dan arah dalam pengaruh kegiatan proses belajar mengajar. Dengan membuat strategi yang baik sesuai dengan kurikulum akan tercapai prestassi belajar yang optimal. Prestasi belajar adalah sesuatu yang dinyatakan dengan nilai yang didapat dan dicapai siswa sebagai hasil dari usaha yang dilakukan dalam berintegrasi dengan lingkungangan (sekolah dan guru dalm proses belajar mengajar).

\section{DAFTAR RUJUKAN}

Ali, Muhammad. 1984. Dalam Proses Belajar Mengajar. Bandung: Sinar baru.

Depdikbud. 1994. Buku Pedoman Proses Belajr Mengajar. Jakarta.

Hamdani. 2011. Strategi Belajar Mengajar. Bandung: Pustaka Setia.

Nawawi, Hadari. 1981. Organisasi Sekolah Dan Pengelolaan Sekolah. Bandung: Alumni.

Rifai, Moh. 1994. Administrasi Dan Supervisi Pendidikan. Bandung: Jemmars.

Roestyah, NK. 2008. Strategi Belajar Mengajar. Jakarta. Rineka Cipta.

Siagian, Sondang. 1990. Filsafat Administrasi. Jakarta: Gunung Mulia. 
SCHOOL EDUCATION JOURNAL VOLUME 9 NO. 2 JUNI 2019 